\title{
Effect of Cognitive Behavioral Treatment Program on Anxiety and Self-Esteem among Secondary School Students
}

\author{
Sayeda Mohamed Mohamed \\ Psychiatric Mental Health Nursing Department, Faculty of Nursing, Cairo University, Cairo, Egypt
}

Email address:

Mohamed_sayeda@yahoo.com

\section{To cite this article:}

Sayeda Mohamed Mohamed. Effect of Cognitive Behavioral Treatment Program on Anxiety and Self-Esteem among Secondary School Students. American Journal of Nursing Science. Vol. 6, No. 3, 2017, pp. 193-201. doi: 10.11648/j.ajns.20170603.17

Received: February 27, 2017; Accepted: March 13, 2017; Published: March 28, 2017

\begin{abstract}
Aim of this study was to investigate the effect of cognitive behavioral treatment program on anxiety level and self-esteem among secondary school students. A Quasi-experimental pre-post non-equivalent group design was used for this study. The study was conducted at El Manial National Language Schools. A convenient sample of thirty secondary school students was selected. The sample was divided into two groups, fifteen students as the study group and fifteen students as control group. Three tools were used to collect the data for the present study; a) Personal Data Sheet; b) Hamilton Rating Scale of Anxiety; and c) Self-esteem Inventory. A constructed cognitive behavioral treatment intervention was developed by the researcher and implemented to the study group in ten sessions that were held twice weekly, and each session ranged from 60 to 90 minutes. The main study findings revealed that, there was a statistically significant difference between study and control groups in the reduction of anxiety level; however, there was no significant change in self-esteem for both groups. The study concluded that, cognitive behavioral treatment program was effective with secondary school students concerning the reduction of the anxiety level. The study recommended that, there is a great need for continuous follow-up of secondary school students who participated in cognitive behavioral treatment program to support and boost their coping strategies with anxiety.
\end{abstract}

Keywords: Anxiety, Self-Esteem, CBT, Students

\section{Introduction}

Adolescence represents to an imperative formative move from youth to adulthood that includes various physiological, mental and social changes. Amid this timeframe, youths encounter a range of stress extending from standard to serious. They may encounter assortment of potential stressors, for example, changes in obligations, higher scholastic prerequisites, diverse interpersonal connections, including associates and companions, guardians and romantic relations, and furthermore worries about one's future. Long term exposure to stress is associated with an assortment of perpetual mental and physiological sickness notwithstanding smoking; tranquilize abuse and high risk for abnormal sexual behavior. Scholastic stress is the significant wellspring of worry among youths and it might prompt to low self-esteem. Numerous mental issues, such as, depression, anxiety and suicide may occur because of low self-esteem $[1,2]$.
Secondary school is a crucial level of guidelines in which adolescents continue taking the fundamental data and capacities that every person must have. At this informative level, youngsters get basic speculation aptitudes; make concurrence with societal qualities, and principal capacities with respect to working in general society field. School exhausts an imperative bit of youth's lives and a basic piece of their time. The school setting is extremely connected with youngsters and their exposure to stress and tension. Troublesome anxiety can be exacerbated in the midst of the secondary school years as students face phenomenal moves and social and academic stressors [3].

[4] found numbers of components were added to create anxiety and low self-esteem among students that included negative experiences in class or with classmates or with teachers. In addition to the individual factors related to the 
maladaptive motivational profile and consolidate a maladaptive student mental self representation, a lower level of self-esteem, and absence of assurance. Moreover, the subjective parts which include lower level of conceptual or sensible thinking, poor scholarly abilities or lacking learning styles are all factors that considered to be the key part in the lead stress among students.

Anxiety is a landmark among the most well-known psychological prosperity mindfulness toward young people. Anxiety can be an extraordinary degree of impact on youngsters, given the importance of success in the midst of times of move. Wellsprings of anxiety and worry can move colossally. Youngsters frequently experience stress when they have other mental issues [5].

Anxiety is thought to be a general phenomenon existing crosswise over societies, in spite of the fact that its specific circumstances and indications are impacted by social convictions and practices. Anxiety is associated with considerable negative consequences on youngsters' social, passionate and scholarly achievement. Particular impacts incorporate poor social and adapting aptitudes, frequently prompting to shirking of social cooperation, depression, low self-esteem, impression of social rejection, and trouble framing friendships. Essentially, school evasion, diminished critical thinking capacities, and lower scholastic accomplishment have additionally been noted as results [6].

Anxiety in adolescents has been appeared to effect scholarly accomplishment, test execution, peer popularity, depression, thinking deficiencies, and depression and in addition other behavioral and social issues. Sadly, a greater number of youths are encountering risky anxiety than are perceived or treated inside the school setting [7].

Levels of anxiety get to be abnormal and can negatively affect the student's intellectual function and, at long term, school performance and outcomes. The prompt outcome is the presentation of errand insignificant thoughts which meddle with the information processing system by making diverting data ready to move the deliberate concentration and decrease space in working memory. High levels of anxiety amid reading or computation meddle with the phonological circle and cause the requirement for articulator practice bringing about diminished working memory limit, deficient data handling and mediocre utilization of meta-cognitive abilities, for example, planning or monitoring techniques [8].

Moreover, high levels of anxiety were found to be associated with physiological side effects, for example, headache, inordinate sweating, muscle spasms, palpitations, and hypertension, which now and again prompt to weariness and fatigue. Those influenced can likewise erupt on occasion of high anxiety [9].

[10] pointed out that, self-esteem is identified with a person's self-acknowledgment of their character and largely affects the improvement of propensities, feelings, behavior and mental adjustment. Significant connections have been found between unreasonable thinking and low self-esteem; these misrepresentations may include abnormal speculations, specific reaping, and an excessive amount of self-reference .
Self-esteem is viewed as one of the determinants of human conduct. Indeed, its people perception and judgment that decides how they manage different issues. A person who has low self-esteem and self-worth and no sense of pride, may endure disengagement, and/ or exhibits hostile to social practices and animosity [11].

Low self-esteem has been related with anxiety symptoms and physiological complains while high self-esteem has been considered as an essential support against anxiety [12, 13]. Cross-sectional research studies found that, there are significant relationships of medium of high measurable power between self-esteem and anxiety [14]. Generally speaking, the accessible research proposes that high selfesteem may have positive results for the prosperity and accomplishment of the individual and that low self esteem might be a risk factor for negative consequences [15].

Furthermore, students with low self-esteem do not take challenges that could likewise bring rewards, for example, advancement of their education and getting them a great name among their groups of friends both in school and at home [16]. Students with low-self-esteem are particularly defenseless against those precarious and negative conditions in light of the fact that their sentiments of self-esteem tend to drop under disappointment, they are more worried about selfsecurity in distressing circumstances, and they will probably have depressive attributions because of negative occasions. They additionally tend to over-generalize the negative outcomes of a distressing circumstance and think that is hard to repair their negative inclinations. The impacts of these maladaptive reactions to unpleasant circumstances can be irritated when stressors are seen as debilitating and uncontrollable, first, in light of the fact that they can additionally obstruct an individual's capacity to adapt effectively and, second, on the grounds that those discernments just check the underlying negative inclinations $[17,18]$.

Treatment and consciousness of stress can be fundamental in decreasing the experience of negative manifestations that can continue for the duration of one's life. Educators, guides, administrators, and companions are all in a vital position to convey attention to stress and teach successful approaches to adapt or overcome anxiety. It is important to move past recognizing and testing unreasonable convictions and automatic thoughts, and manage the pattern inside which they are inserted [19].

Cognitive Behavioral Therapy (CBT) had been an imperative piece of viable mental treatments for a large portion of behavioral issues. CBT helps students to encourage versatile abilities that can be useful and successful in future. A few patients affirm that in spite of the fact that they perceive that some of their thoughts are not consistent and safe; this mindfulness does not help ceasing them. CBT does not talk about distinguishing proof of mental patterns; rather it concentrates on the utilization of various sorts of methodologies keeping in mind the end goal to help patients beat these thoughts. Among these methods we can allude to day by day note-taking, role playing and relaxation [20]. 
The CBT therapist teaches clients how to distinguish distorted thoughts through the procedure of re-evaluation. They figure out how to separate between their own contemplations and reality. CBT helps people to create elective methods for intuition and carrying on which may decrease their level of harassing. People who authorize tormenting practices have flawed or misshaped thinking design. These examples come from what he called "cognitive schemas" which are profoundly held general articulations that aggregate up the presumptions the client hold about the world. They are core beliefs that predisposition the way we see and translate our encounters. Negative schemas like "everybody hates me", "I need to use force to get what I want or I will never have them" "life is war", "I am angry with everyone" give rise to faulty thinking patterns in day to-day situations and therefore contribute to anxiety, depression, frustration, anger, aggression, and other psychological and behavioral problems. The aim of therapy is to help people recognize and change their faulty thinking patterns and bullying behaviors [19].

CBT interventions in a school setting would for the most part be concerned with helping students acknowledge three things: how their thought patterns influence their behavior, how they can take control of these thought patterns and how they can apply interventions to impact their behavior change. Recently, school instructors have been especially much mindful of how their interventions add to the expansion of student scholastic accomplishment [21].

[22] examined the effectiveness of cognitive behavioral techniques including Cognitive Restructuring, Coping Skills Training, mainly Problem solving, Social Skills training and effective study habits on high school student's academic stress ( 30 boys and 30 girls), (aged between 13 to 16 years) for a period of three months, five days a week, and found decreased high school student's academic stress and enhanced their mental well-being. They suggested that while the academic stress of the students of experimental group decreased significantly, and a significant enhancement in well being.

Significance of the study

Many students do not do well in school because they are suffering from school stress. This situation leads to anxiety, depression and poor academic performance in these students, so it is important to identify these adolescents and use the suitable ways to reduce their stress. The cognitive behavioral interventions reduce stress, and increase the academic achievement of student in high schools.

Troublesome anxiety can be exacerbated during the secondary school years as students face extreme transitions and social and academic pressures. If students are not able to recognize when they have a problem with anxiety they can suffer physically, socially, academically, and emotionally. Effective coping skills can help adolescents overcome many of the challenges they face during adolescence and throughout life. Awareness and treatment of anxiety can be crucial in reducing co-morbidity among mental health problems. Previous research in Egypt who reported that,
$41.2 \%$ had significant anxiety symptoms among secondary school students [23].

Self-esteem plays an important role in stress experienced by students. In particular, students with high self-esteem can efficiently manage stress and therefore have better academic performance. Finally, there are many stress management techniques that improve people's self-esteem for example yoga, meditation, humor, mindfulness and counseling.

Low self-esteem is a major problem in the secondary school students. Anxiety also usually has an effect on a student's self esteem and well-being; it may be an adverse effect. Anxiety can affect aspects of students' lives that are of the utmost importance to them including learning and performance in educational settings and professionalism after that. Treating anxiety in educational settings reveals that there are still very few proven programs of intervention to be effective. However, research studies proved that nonpharmacological interventions are effective in stress and anxiety reduction, and intervention programs have shown promise in managing the negative effects of these emotional responses.

Nurses are expected to assume responsibility for the protection and improvement of mental health because of their counseling, psychotherapy and research roles. One of the psychotherapeutic fields that psychiatric nurses can participate in is cognitive behavioral therapy. Cognitive behavioral therapy is an effective, problem-oriented, shortterm, cost-effective, evidence-based approach that psychiatric nurses can use. However, studies demonstrating the effectiveness of cognitive behavioral intervention applied by nurses are few, and the relevant evidence is very scarce.

Additionally, there is a research gap exists pertaining to application of specific CBT interventions in secondary schools. However, not only do the CBT interventions showed the effectiveness in reducing anxiety, but also the effectiveness of CBT for improving students' self-concept and positively affecting academic achievement. Therefore, the current study will shade the light on the role of the liaison nurse in using cognitive behavioral techniques to help the student to develop alternative behaviors / attitudes of behaving during periods of stress instead of engaging in maladaptive behaviors.

\section{Aim of the Study}

The aim of this study is to investigate the effect of CBT program on anxiety and self-esteem among secondary school students.

\section{Research Hypotheses}

H1: Secondary school students who participated in the CBT program will have reduced anxiety level than the control group.

H2: Secondary school students who participated in the CBT program will have improved self-esteem than the control group. 


\section{Material}

\subsection{Research Design}

A quasi-experimental pre-posttest non-equivalent group design was used in this study to investigate the effect of CBT program on anxiety and self-esteem among secondary school students.

\subsection{Setting}

This study was conducted at El Manial National Language Schools.

\subsection{Sample}

A convenient sample was used in the current study. It consists of fifty secondary school students in third year at the school. Actual students who completed the pre-test were thirty five students, five students refused to continue after the second session. Thirty students were matched by gender and the scores they obtained from the scale and were randomly assigned in to two groups. The experimental group included fifteen (female, male) students; the control group included fifteen (female, male) students. All participants (study and control groups) were assessed at baseline (T1), then three months later at the end of the program (T2).

Inclusion criteria

1- Age ranged from 16 to 18 years old. The ninth-year students were selected for the study because they were in the 16-18 years age group, an age when adolescents tend to display anxious behaviors more intensely. In addition, implementing such a program in the ninth-year students was thought to offer a preventive role for the coming years.

2- Male and female students.

3 - Students in second /or third year of the secondary school.

4- The student who were described as an easily provoked to anger by their social worker or teachers.

\subsection{Tools}

For the purpose of the study and to collect the necessary data, one tool was developed by the researcher and two tools utilized based on review of literature.

Tool 1: Persona Data Sheet:

It was developed by the researcher to draw out information about students' gender and type of accommodation.

Tool II: Self-esteem Inventory:

It self-report questionnaire that was developed by [24]. It is and used to measure global self-esteem in both high school students and adult population. It consisted of thirty- nine items. The Arabic version of this tool was translated by [25]. It is categorized under four subscales; the first subscale is about self esteem by family ( 9 items), the second subscale which represents self esteem by school (10 items), the third subscale is self esteem by peer (10 items) and the fourth subscale is about self esteem by general (10 items). The tool is on a five point likert scale, ranging from " $(5=$ strongly agree) to $(1=$ strongly disagree $)$. The negative statements in this tool are (items from first subscale: 2, 8, and 9), four items are negative from second subscale (items- 3, 5, 7, and 9), six items from third subscale (items: 2, 3, 4, 6, 8 and 10), and five items from fourth subscale (2, 5, 7, 8 and 10). Total score is calculated by summations of items ranged from (39195). High scores indicate high self esteem among students. The internal consistency reliability (Cronbach's $\alpha=.83$ ) of the scale which is adequate.

Tool III: Hamilton Rating Scale of Anxiety:

It was developed by (Hamilton, 1950) to measure the severity of anxiety symptoms, and is still widely used today in both clinical and research settings; it was translated into Arabic by [26]. It is composed of 14 items each of which is scored $(0-2)$ or $(0-4)$. The score zero is typically individual, the score $(1=$ mild level $)$, the score $(2$ $=$ moderate), the score $(3=$ severe level $)$, and the score (4=grossly disabling). Total score is ranging from (0-56). Hamilton Rating Scale of Anxiety takes approximately 15$30 \mathrm{~min}$ to administer and score. To determine the severity of anxiety the following scores are used $(\leq 17)$ indicates mild anxiety; $(18-24)$ indicated moderate anxiety; this degree of anxiety can be handled by teaching the patient coping techniques such as meditation and breathing exercises. $(\geq 25)$ indicated severe anxiety; this level of anxiety may require medication to help bring the anxiety under control well enough that the patient can then learn to use relaxation techniques and programs like CBT to overcome their anxieties once and for all.

Validity appears good, based on correlation with other anxiety scale. Reliability is fairly good, based on internal consistency (alpha $=0.77$ to 0.92 ) [27], inter-rater, and test retest studies. It has been used extensively to monitor treatment response in studies of general anxiety disorder and may also be useful for this purpose in clinical settings [28]

Program Description

A structured nursing intervention of cognitive-behavioral techniques was developed by the researcher based on related review of literature. This program consisted of three phases: Assessment (three sessions) to assess secondary school students by using questionnaire sheets; implementation (ten sessions) to implement nursing cognitive behavioral interventions with study group; and in evaluation phase (two sessions) to evaluate all secondary school students by using questionnaire sheets.

The program included fifteen sessions that were held twice weekly, with (60-90) minutes for each.

Assessment phase. This phase was conducted in three sessions (included the study instruments): personal data sheet, Hamilton Rating Scale of Anxiety and Self-Esteem Scale. These pre-assessment questionnaires were completed by all participants (experimental and control groups) at baseline measurement.

Implementation phase. This phase consisted of 10 sessions; the first session focused on establishing trust relationship with students, maintaining the students' engagement in the treatment, and orienting the students to the CBT model. The researcher emphasized on confidentiality 
and maintaining student's privacy. The researcher explained the aim of the study, meeting time was twice per week from (10.00 am - to 11: $30 \mathrm{am}$ ). The first session included introduction and important information about the nature of adolescence period and related physical and psychological changes and how it is associated with anxiety and self-esteem among adolescents.

Second session was designed to identify psychological problems that the secondary school students suffer from resulting from their anxiety and methods of coping that are followed by them. The therapist offered number of the most psychological problems that the secondary school students suffer from and solutions for them.

Session three: focused on Self-observation methods; session (four and five): were related to the positive thinking training and stress inoculation. The sixth session concentrated on the Cognitive restructuring. The seventh session was on problem solving training. Session number eight was focusing on Assertive imaginary. The ninth session was related to time management. The tenth session was focusing on reviewing the previous sessions and preparing the students for the end of the therapy.

Every skill was performed by using learning techniques which included instructions, role play and re-play, feedback, and reinforcement, modeling and practicing in different situations in group sessions; and finally followed by homework assignment for every skill that was revised at the beginning of each session.

Evaluation phase. This was the final phase where the evaluation of the program was done through the same relevant selected Hamilton Rating Scale of Anxiety and Rosenberg's Self-Esteem Scale. This post assessment was done by the researcher for all subjects including the study and control groups. This matter helped the researcher to determine the effect of the program on anxiety and self esteem among secondary school students.

\section{Methods}

After obtaining the official approval from the Ethical Committee of Scientific Research at the Faculty of Nursing, Cairo University as well as official approval from director of Masr El Khdema educational administration, and also from director of El Manial National Language Schools. The researcher interviewed all participants before they enter the program. The purpose of the study was explained and oral consent was obtained, then written consent was obtained immediately before filling the tools. The purpose of the study was explained for teachers and social worker of all selected classes for students to gain support and corporations. Fixed time and room were determined for program sessions. Students maintained on their regular daily activities at the school, in combination with the cognitive - behavioral treatment program.

The researcher used semi-structured interview to complete tools for students assessment, this interviewed lasted for about (30-45) minutes, also the researcher observed the students communications and interactions with other students during implementation of the program.

\section{Statistical Analysis}

Data were analyzed by using the Statistical Package for the Social Sciences statistical software (SPSS version 20). Descriptive statistics were computed to examine data distributions and summarize data. According to the baseline scores of the Hamilton rating scale of anxiety and Rosenberg self-esteem scales, comparison was done between pre/ post and follow up assessment for study group using paired- $t$ test. Mean change was used to calculate the change after program sessions, Reported $\mathrm{p}$ values with level of significance set at $\mathrm{p}$ $<.05$.

\section{Results}

This study was conducted on thirty secondary school students to investigate the effect of cognitive behavioral treatment program on anxiety and self esteem.

Table one: shows personal data of secondary school students namely gender and type of accommodation. Males were $(70 \%)$ and $(30 \%)$ females. Concerning type of accommodation showed there were $(80 \%)$ stay with their family and $(20 \%)$ stay with relatives.

Table two: shows that the Hamilton rating scale of anxiety mean scores for the experimental group was significantly different between mean scores for the pre program (38.93 \pm 4.80$)$ and for post program (23.53 \pm 8.06$)$. The statistical analysis proved highly significant $(\mathrm{t}=6.351$, $\mathrm{p}=0.001$ ). For the control group, there was a decline in the students' post program intervention mean scores $(35.60 \pm 5.64$ to $34.06 \pm 6.52)$ respectively. In relation to the self esteem of secondary school students, there was no significantly different between mean scores for the pre and post program.

Table three: represents that there were highly significant difference between experimental and control groups. For the experimental group, there was a significant reduction in the total level of anxiety according to the mean scores for the pre program (38.93 \pm 4.80$)$ and for post program intervention $(23.53 \pm 8.06),(\mathrm{t}=6.855, \mathrm{p}=.001)$. This indicated significant decline of anxiety levels related to psychic symptoms as tension, fear, and Intellectual and also, in relation to the somatic symptoms such as gastrointestinal, genitourinary, cardiovascular and respiratory symptoms and insomnia.

Table four: illustrates that, there were no significant statistical differences between the experimental and control groups in the pre and post measurements in relation to self-esteem.

Table five: shows that, there was a reduction in students' anxiety that was high and ranged between from (19.0032.00). Regarding self esteem the table revealed mild improvement. Concerning dimensions of self esteem, the familial self esteem ranged from 9- 11, self-esteem by school ranged from 7-19, self-esteem by peer had no change and self-esteem in general ranged 12-16. Improvement of anxiety occurred for the experimental group who received the 
cognitive behavioral treatment program.

Table six: reveals that, there were no statistically significant relations between the students' gender with anxiety and self-esteem.

Table seven: demonstrates that there were no statistically significant difference between students' type of accommodation and their anxiety and self esteem.

Table eight: shows that there was no statistical significant relationship between anxiety scale and self esteem scale $(\mathrm{r}=0.182)$.

Table 2. Comparison between the Experimental and Control Group Regarding Dependent Studied Variables (Hamilton Rating Scale of Anxiety and self esteem) Pre and Post Program Intervention $(n=30)$.

\begin{tabular}{|c|c|c|c|c|c|}
\hline Variables & Group & Pre Mean \pm SD & Post Mean \pm SD & t-test & $\mathbf{p}$ \\
\hline Anxiety: & $\begin{array}{l}\text { Experimental } \\
\text { Control }\end{array}$ & $\begin{array}{l}38.93 \pm 4.80 \\
35.60 \pm 5.64\end{array}$ & $\begin{array}{l}23.53 \pm 8.06 \\
34.06 \pm 6.52\end{array}$ & 6.855 & $0.001 * *$ \\
\hline Self esteem & $\begin{array}{l}\text { Experimental } \\
\text { Control }\end{array}$ & $\begin{array}{l}126.40 \pm 9.61 \\
132.46 \pm 15.09\end{array}$ & $\begin{array}{l}127.00 \pm 7.48 \\
132.93 \pm 13.37\end{array}$ & -0.042 & 0.967 \\
\hline
\end{tabular}

* Statistical significant at $\mathrm{P}<0.05$

Table 3. Differences of Hamilton Rating Scale of Anxiety among secondary school students in the Experimental and Control Groups before and after Program Intervention $(n=30)$.

\begin{tabular}{|c|c|c|c|c|c|}
\hline Hamilton Rating Scale of Anxiety & Group & Pre Mean \pm SD & Post Mean \pm SD & t-test & $\mathbf{P}$ \\
\hline \multirow{2}{*}{ Anxious mood } & Experimental & $2.20 \pm 1.082$ & $1.40 \pm .828$ & \multirow{2}{*}{1.525} & \multirow{2}{*}{0.138} \\
\hline & Control & $2.27 \pm 1.163$ & $2.13 \pm 1.187$ & & \\
\hline \multirow{2}{*}{ Tension } & Experimental & $2.93 \pm 1.033$ & $1.73 \pm .884$ & \multirow{2}{*}{2.799} & \multirow{2}{*}{$0.009 *$} \\
\hline & Control & $2.73 \pm 1.163$ & $2.53 \pm 1.187$ & & \\
\hline \multirow{2}{*}{ Fears } & Experimental & $3.07 \pm .884$ & $1.53 \pm .990$ & \multirow{2}{*}{5.002} & \multirow{2}{*}{$0.001 *$} \\
\hline & Control & $2.93 \pm 1.100$ & $2.93 \pm 1.100$ & & \\
\hline \multirow{2}{*}{ Insomnia } & Experimental & $2.73 \pm .594$ & $1.60 \pm .828$ & \multirow{2}{*}{3.786} & \multirow{2}{*}{$0.001^{*}$} \\
\hline & Control & $2.27 \pm 1.163$ & $2.20 \pm 1.082$ & & \\
\hline \multirow{2}{*}{ Intellectual (cognitive) } & Experimental & $1.60 \pm .986$ & $1.00 \pm .000$ & \multirow{2}{*}{2.358} & \multirow{2}{*}{$0.026^{*}$} \\
\hline & Control & $1.33 \pm .488$ & $1.33 \pm .488$ & & \\
\hline \multirow{2}{*}{ Depressedmood: } & Experimental & $2.20 \pm 1.320$ & $1.33 \pm . .900$ & \multirow{2}{*}{1.612} & \multirow{2}{*}{0.118} \\
\hline & Control & $3.07 \pm 1.100$ & $2.93 \pm 1.033$ & & \\
\hline \multirow{2}{*}{ Somatic (muscular) } & Experimental & $3.40 \pm 1.242$ & $2.27 \pm 1.438$ & \multirow{2}{*}{-.366} & \multirow{2}{*}{0.717} \\
\hline & Control & $3.13 \pm 1.407$ & $2.67 \pm 1.496$ & & \\
\hline \multirow{2}{*}{ Somatic (sensory) } & Experimental & $2.67 \pm 1.291$ & $1.80 \pm 1.146$ & \multirow{2}{*}{1.540} & \multirow{2}{*}{0.135} \\
\hline & Control & $3.27 \pm .799$ & $3.20 \pm .775$ & & \\
\hline \multirow{2}{*}{ Cardiovascular symptoms: } & Experimental & $2.80 \pm 1.146$ & $1.40 \pm .507$ & \multirow{2}{*}{3.974} & \multirow{2}{*}{$0.001 * *$} \\
\hline & Control & $2.53 \pm 1.125$ & $2.40 \pm 1.242$ & & \\
\hline \multirow{2}{*}{ Respiratory symptoms: } & Experimental & $3.93 \pm .258$ & $2.00 \pm 1.363$ & \multirow{2}{*}{4.872} & \multirow{2}{*}{$0.001 * *$} \\
\hline & Control & $3.07 \pm 1.438$ & $2.93 \pm 1.438$ & & \\
\hline \multirow{2}{*}{ Gastrointestinal symptoms: } & Experimental & $2.47 \pm 1.30$ & $1.67 \pm 1.04$ & 237 & $0.05 *$ \\
\hline & Control & $1.27 \pm .88$ & $1.27 \pm .88$ & 2.31 & $0.05^{\circ}$ \\
\hline & Experimental & $3.00 \pm 1.13$ & $1.87 \pm .83$ & & \\
\hline Genitourinary symptoms: & Control & $2.73 \pm 1.22$ & $2.67 \pm 1.29$ & 3.186 & $0.001 \%$ \\
\hline & Experimental & $3.20 \pm 1.20$ & $2.07 \pm 1.100$ & 3284 & \\
\hline Autonomic symptoms: & Control & $2.73 \pm 1.38$ & $2.60 \pm 1.35$ & 3.284 & $0.003^{*}$ \\
\hline Behavior at interview: & Experimental & $2.73 \pm 1.43$ & $1.87 \pm 1.45$ & 2476 & $0020 *$ \\
\hline Denavior at minerview. & Control & $2.27 \pm 1.62$ & $2.27 \pm 1.624$ & & 0.020 \\
\hline Total experimental & & $38.93 \pm 4.80$ & $23.53 \pm 8.06$ & 6.855 & $0.001 * * *$ \\
\hline Total control & & $35.60 \pm 5.64$ & $34.06 \pm 6.52$ & & \\
\hline
\end{tabular}

Statistically significant at $\mathrm{P}<0.05^{*}$

Table 4. Difference of Mean Scores of self esteem domains among secondary school students in the Experimental and Control Groups PrelPost Program Intervention $(n=30)$.

\begin{tabular}{lllll}
\hline Domains of Self esteem Scale & Group & Pre Mean \pm SD & Post Mean \pm SD & t-test \\
\hline \multirow{2}{*}{ self-esteem by family } & Experimental & $28.60 \pm 3.35$ & $30.06 \pm 2.31$ & $-1.00 \pm 4.12$ \\
& Control & $31.00 \pm 4.259$ & $31.00 \pm 0$ & $32.20 \pm 2.14$ \\
\multirow{2}{*}{ self-esteem by school } & Experimental & $31.80 \pm 5.55$ & $33.00 \pm 5.04$ & -0.272 \\
\hline
\end{tabular}




\begin{tabular}{|c|c|c|c|c|c|}
\hline Domains of Self esteem Scale & Group & Pre Mean \pm SD & Post Mean \pm SD & t-test & $\mathbf{p}$ \\
\hline \multirow{2}{*}{ self-esteem by peer } & Experimental & $33.60 \pm 3.83$ & $32.0000 \pm 3.25$ & \multirow{2}{*}{0.720} & \multirow{2}{*}{0.477} \\
\hline & Control & $33.46 \pm 5.27$ & $33.06 \pm 5.02$ & & \\
\hline \multirow{2}{*}{ self-esteem in general } & Experimental & $32.40 \pm 4.33$ & $32.73 \pm 3.57$ & \multirow{2}{*}{-1.163} & \multirow{2}{*}{0.256} \\
\hline & Control & $35.00 \pm 6.33$ & $35.8667 \pm 6.01$ & & \\
\hline Total experimental & & $126.40 \pm 9.61$ & $127.00 \pm 7.48$ & \multirow{2}{*}{-0.042} & \multirow{2}{*}{0.967} \\
\hline Total control & & $132.46 \pm 15.09$ & $132.93 \pm 13.37$ & & \\
\hline
\end{tabular}

Table 5. Range of Improvement Pre-Post intervention regarding Dependent Variables (Anxiety, and self esteem) among the Experimental Group $(n=15)$.

\begin{tabular}{ll}
\hline Variables & Range \\
\hline -Anxiety: & $19-32$ \\
Self-esteem: & \\
self-esteem by family & $9-11$ \\
self-esteem by school & $7-19$ \\
self-esteem by peer & $11-11$ \\
self-esteem in general & $12-16$ \\
Total & $39-57$ \\
\hline
\end{tabular}

Table 6. Differences between Male \&Female (Experimental group) in the Improvement as Regard to Anxiety, self esteem $(n=15)$.

\begin{tabular}{lllll}
\hline Variables & Male Mean \pm SD & Female Mean \pm SD & t-test & p \\
\hline - Anxiety & $22.27 \pm 8.78$ & $27.00 \pm 2.64$ & -1.004 & 0.334 \\
- self-esteem & $126.90 \pm 6.87$ & $127.25 \pm 10.17$ & -0.75 & 0.941 \\
\hline
\end{tabular}

Table 7. Differences among type of accommodation in the Experimental Group in relation to Improvement of Dependent Variables (Anxiety, Pain and Quality of life Scale) $(n=15)$.

\begin{tabular}{lllll}
\hline variables & $\begin{array}{l}\text { With family } \\
\text { Mean } \pm \text { SD }\end{array}$ & $\begin{array}{l}\text { With Relatives } \\
\text { Mean } \pm \text { SD }\end{array}$ & t-test & p \\
\hline - Anxiety & $24.00 \pm 9.64$ & $22.83 \pm 5.70$ & 0.265 & 0.795 \\
- self esteem & $128.33 \pm 8.39$ & $125 \pm 6.00$ & 0.836 & 0.418 \\
\hline
\end{tabular}

Table 8. Correlation Matrix between Totals Mean of the Experimental Group as Regarding Improvement in Hamilton Rating Scale of Anxiety, and self esteem scale.

\begin{tabular}{ll}
\hline Variables & Anxiety \\
\hline Self-esteem & $\mathrm{r}=0.182, \mathrm{p}=0.516$ \\
\hline
\end{tabular}

*Statistical significant at $\mathrm{P}<0.05$

$\mathrm{r}=$ person correlation

$\mathrm{P}=$ level of significance

\section{Discussion}

Anxiety has been found to be the most reported psychopathology in adolescence. Anxiety is one of the most prevalent mental health concerns for adolescents. Adolescents often experience anxiety for a variety of reasons including, transitions, life pressures, and maturation. This study aimed to investigate the effects of cognitive behavioral treatment program on anxiety and self esteem among secondary school students.

The distribution of the sample according to their gender and type of accommodation of the present study (Table 1) showed that, about three fourth of the sample was male while the rest of the sample were female, while the most of the participants reported they lived with their parents while the rest of the sample indicated that lived with their relatives. This result could be due to occurrence of anxiety is similar between male and female. Females appear to experience anxiety more than males. But, female embarrassed to express their feeling of anxiety in front others. This is leading to female are less willing to share about their experiences with anxiety. This result was in incongruent with [29] who revealed that, male may experience more extreme anxiety when they have it, but have a lower overall prevalence than females. Approximately $20 \%$ more females participated in the study, which could indicate that males are less willing to share about their experiences with anxiety.

Regarding the effectiveness of cognitive behavioral treatment program among secondary school students, there were statistically significant changes post interventions than before regarding participants' anxiety where pre intervention (table 2). This finding could be interpreted as CBT was effective in reducing anxiety in secondary school students because of the CBT was focused on the way in which a adolescents interpreted his/her experiences and how these thoughts ultimately influenced on his or her emotional and behavioral functioning to reduce the psycho-physiological activation that is associated with stress management approaches (e.g. deep breathing practice was taught to subjects and they asked to practice it regularly. Using this technique regularly can reduce the physiological symptoms of stress. This finding was congruent with [30, 31] who confirmed the efficacy of CBT in alleviation of academic stress symptoms and enhancing academic performance.

Regarding the scores of self-esteem in experimental and control groups pre/post the program intervention were tested and the results indicated that, there was no significant improvement in self esteem and its domains among secondary school students. The possible explanation of these findings is that the program applied in this study included techniques such as, relaxation techniques, role-play, coping self-talk, and exposure modeling could significantly reduce anxiety. Self-esteem was not improved due to high levels of anxiety among secondary school students that affected student self esteem. On basis increase in self-esteem necessary to improve one or more areas of the field of behavioral, cognitive, emotional and biological in person and cannot be directly increased self-esteem. This finding was inconsistent with [20] who revealed that, there is great difference significance in self-esteem level between students who receive cognitive- behavioral trainings and students who doesn't receive such trainings. Additionally, [32] compared the effectiveness of a cognitive - behavioral therapy on selfesteem and the reality of high school students with a positive impact of increasing self-esteem in the experimental group.

In relation to the differences between male and female according to the anxiety level and self-esteem, the current study revealed no significant difference between males and 
females in the total score of anxiety and self esteem (table 6). A probability explanation for these findings is that, males and females hold the same awareness to ward family school and friends. Additionally, they share the same social norms and beliefs that affected their self esteem.

This result is consistent with the results obtained by [1] who found no difference in the means of self-Esteem Inventory (SEI) between male and female. Also, ${ }^{(1)}$ found no significant gender difference between males and females in self-esteem. With respect to the sub scales scores, there was no significant gender difference in the home/parental, academic, social and general self-esteem. These findings suggest that feelings towards family, parents, peers and friends are similar between males and females. The findings suggest that males and females hold similar perceptions of schools, friends, and parents. Their psychosocial development yields similar selfesteem between males and females.

As regards to type of accommodation, the present study revealed that, there were no significant differences between student stay with family and students stay with their relatives (table 7). This finding may be due to students experienced the same sources of anxiety as need helping in how to manage their time and to allocate enough time to each subject (Maths, English, and computer), subjects based on their priority and importance helped to reduce time pressures and provides opportunities to other social activities, personal hobbies and interests. This finding was consistent with [33] who found that, there were no significant differences in the level of anxiety by gender and area of residence.

Concerning the relationship between anxiety and self esteem among secondary school students (table 8). The current study demonstrated that, there were no significant relationship between anxiety and self esteem. These results could be due to adolescents with low self-esteem has high anxiety or adolescents with high anxiety can have low selfesteem. Individuals with high self-esteem are less stressful in different situations and are less emotional, depressed and aggressive. Those with low self-esteem suffer from aggressiveness, behavioral disorder and grief. Moreover, these individuals complain from insomnia and psychosomatic diseases. Self-esteem especially appears in mutual transactions: those who believe in themselves, love others, and accept their weaknesses can find more and better friends.

The results of the study contributed to the facts that anxiety reduction strategies can be learnt.

\section{Conclusion}

This study concluded that CBT intervention was effective approach in reducing anxiety among secondary school students. There was a negative correlation between the anxiety and self esteem of the studied sample. One of the strengths of the present study was its focus on improvement of important factors related with anxiety as common problems of teenager students. Important potential weakness of current study was using self-report inventories based on the participants' responses which may affect the results.

\section{Recommendations}

Based on the findings of the present study the following recommendations are suggested:

- Students with anxiety should be encouraged to receive psychotherapeutic trainings like Cognitive Behavior Therapy.

- School administration boards and the Ministry of Education should equip the schools with trained Guidance Counselors in a good ratio to the population of the students in each school.

- School authorities should encourage the use of psychotherapeutic methods to modify students' undesirable behaviors such as anxiety.

- Continuous follow-up for secondary school students who participated in cognitive behavioral treatment program to support and boost their coping strategies.

- Further studies need to recruit more samples from each grade, to establish comprehensive counseling trainings for students about how to enhance their interpersonal relations with parents, teachers and classmates.

- Further studies should involve the students and their parents to participate together in the intervention program, because most of the studied students reported that they had some interpersonal problems with their parents.

- School Guidance Counselors should make use of CBT to enhance the student's self-esteem.

- Holding stress management workshops in the schools and implementing psychotherapy training programs can improve the mental health of the students.

\section{References}

[1] ElRafei, S. (2008). The Relationship between Self-Esteem and Gender, Grade Level and Academic Achievement, in Secondary Schools' Classes in Lebanon. Thesis submitted for the degree of Doctor of Education At the University of Leicester.

[2] Nikitha, S., Jose, T., \& Valsara, B. (2014). A Correlational Study on Academic Stress and Self - Esteem Among Higher Secondary Students in Selected Schools of Udupi District. Nujhs Vol. 4, No. 1, Issn 2249-7110.

[3] Yılmaz, M., \&Ocakçı, F. (2010). Determination the Anxiety Level of University Students' one Dormitory located. MaltepeUniversitesiHemsirelikBilimveSanatıDergisi, 3 (1), 16-23.

[4] Hisken, L. (2011). The Correlation between Self-Esteem and Student Reading Ability, Reading Level, and Academic Achievement. Paper submitted in partial fulfillment of the requirements for the degree of Master of Science in Library Science and Information Services in the Department of Educational Leadership and Human Development University of Central Missouri.

[5] Costello, E. J., Copeland, W., \&Angold, A. (2011). Trends in psychopathology across the adolescent years: What changes when children become adolescents, and when adolescents become adults? Journal of Child Psychology and Psychiatry, (52) 10, 1015-1025. doi: 10.1111/j.1469-7610.2011.02446.x. 
[6] Deb, S., \& Walsh, K. (2010). Anxiety among high school students in India. Comparisons across gender, school type, social strata and perceptions of quality time with parents. Australian Journal of Educational \& Developmental Psychology. Vol 10, pp 18-31.

[7] Luigi, M., Francesca, D., Maria, D. S., Eleonora, P., Valentina, G. D., \& Benedetto, V. (2007). The Role of Anxiety Symptoms in School Performance in a Community Sample of Children and Adolescents. BMC Public Health; 7: 347. Doi: 10.1186/1471-2458-7-347.

[8] Pereira AIF, Barros L, Mendonça D (2012) Cognitive Errors and Anxiety in School Aged Children. Psicologia: Reflexão e Crítica, 25: 817-823.

[9] Frank-Briggs, A., \& Alikor, E. (2010). Anxiety Disorder amongst Secondary School Children in an Urban City in Nigeria. Int J Biomed Sci.; 6 (3): 246-251.

[10] Attar, S., Farahani, M., \&Hidaji, M. (2015). Effect of Cognitive-Behavioral Group Intervention (CBT) on Students' Self-Esteem. Int. J. Rev. Life. Sci., 5 (4), 2015, 1098-1102.

[11] Siahkalroudi, S., \&Bahri, M. (2015). Effectiveness of Cognitive Behavioral Play Therapy Group on Self-Esteem and Social Skills in Girls' Elementary School. Journal of Scientific Research and Development 2 (4): 114-120, 2015.

[12] Millings, A., Buck, R., Montgomery, A., Spears, M., \&Stallard, P. (2012). School Connectedness, Peer Attachment, and Self-Esteem as Predictors Of Adolescent Depression. Journal of Adolescence, 35, 1061-1067.

[13] Morley, T. E., \& Moran, G. (2011). The Origins of Cognitive Vulnerability in Early Childhood: Mechanisms Linking Early Attachment to later Depression. Clinical Psychology Review, 31, 1071-1082.

[14] Lee, A., \&Hankin, B. L. (2009). Insecure Attachment, Dysfunctional Attitudes, and Low Self-esteem Predicting Prospective Symptoms of Depression and Anxiety during Adolescence. Journal of Clinical Child and Adolescent Psychology, 38, $219-231$.

[15] Sowislo, F., \& Orth, U. (2013). Does Low Self-Esteem Predict Depression and Anxiety? A Meta-Analysis of Longitudinal Studies. Psychol Bull.; 139 (1): 213-40. doi: 10.1037/a0028931.

[16] Ahmad, I., Zeb, A., Ullah, S., \& Ali, A. (2013). Relationship between Self-Esteemand Academic Achievements of Students: A Case of Government Secondary Schools in District Swabi, KPK, Pakistan. International J. Soc. Sci. \& Education 2013 Vol. 3 Issue 2, ISSN: 2223-4934.

[17] Nima, A., Rosenberg, P., Archer, T., \& Garcia, D. (2013). Anxiety, Affect, Self-Esteem and Stress: Mediation and Moderation Effects on Depression. PLoS ONE, 8, e73265. http://dx.doi.org/10.1371/annotation/49e2c5c8-e8a8-4011$80 \mathrm{fc}-02 \mathrm{c} 6724 \mathrm{~b} 2 \mathrm{acc}$.

[18] Galanakis, M., Palaiologou, A., Patsi, G., Velegraki, I.-M., \&Darviri, C. (2016). A Literature Review on the Connection between Stress and Self-Esteem. Psychology, 7, 687694.http://dx.doi.org/10.4236/psych.2016.75071.

[19] Olatunbosun, I. (2016). Efficacy of Cognitive Behavior Therapy on Reducing Bullying Behavior among Secondary School Students in Ikwerre Local Government Area.
Academia Journal of Educational Research 4 (1): 001-007.

[20] Shaarbaf, H., Timuri, S., Sanadgol, M., \& Gazidari, E. (2015). Assessment of Effectiveness of Cognitive-Behavioral Group Training on Self-Esteem and Achievement Motivation of High School Students. Future of Medical Education Journal, Volume 5, Issue 4, December 2015, Page 14-19.

[21] Clark, F. (2010). Preventing Future Crime with Cognitive Behavior Therapy. Journal of National Institute Of Justice, 265.

[22] Sharma, K., Shrivastava, S., Malh Sharma, UK, Shrivastava, S., Malhotra, S., Singh, R., \& Singh, B. (2010). Yoga and Cognitive Behavior Techniques for Academic Stress and Mental Wellbeing amongSchool Students. Delhi Psychiatry Journal 13 (1).

[23] Al Bahnasy, R., Abdel-Rasoul, G., Mohamed, O., Mohamed, N., \&Ibrahem, R. (2013). Prevalence of Depression, Anxiety, and Obsessive-Compulsive Disorders among Secondary School Students in Menoufia Governorate, Egypt. Menoufia Medical Journal 2013, 26: 44-48.

[24] Coopersmith, S. (1981). Self-esteem Inventories. Palo Alto, CA: Consulting Psychologists Press Inc.

[25] Didana, A. (2003): Self-Esteem and its Relation to Aggressive Behavior among Middle School Students in Riyadh, Master Thesis, Qaboos University, Amma.

[26] Fattin, L. (1997). Hamilton Rating Scale of Anxiety. The Anglo-Egyptian Library.

[27] Maier, W., Buller, R., Philipp, M., \& Heuser, I. (1988). The Hamilton AnxietyScale: Reliability, Validity and sensitivity to Change in Anxiety andDepressive Disorders. J Affect Disord; 14 (1): 61-8.

[28] Sadock, B., \&Sadock, A. (2000). Comprehensive Textbook of psychiatry. Vol. I, ( $7^{\text {th }}$ ed.). London, Lippincott Williams \&Willikins. Pp 193-197.

[29] Hess, J. (2014). "Anxiety Prevalence among High School Students". Counselor Education Master's Theses.

[30] Rice, C. (2008). Reducing Anxiety in Middle School and High School Students: A Comparison of Cognitive Behavioral Therapy and Relaxation Training Approaches. Partial fulfillment of the requirements for the degree of doctor of philosophy with major in school psychology, University of Arizona.

[31] Arefi, K., Momeni, F., \&Mohsenzadeh, R. (2012). Comparison of Individual Cognitive Therapy and Relaxation Therapy in the Treatment of High School Student's Academic Stress. Journal of Kermansha University Of Medical Sciences 1 (1) $32-46$

[32] Forghani, Toroghi, Ommolbanin, Javanbakht, Mar-yam, Bayazi, Mohammad Hossein, Sahebi, Ali, Vahi-di, Shoaib, Doroudgar, Khadijeh (2011), "Comparison of the effectiveness of a cognitive - behavioral therapy and reality therapy on self-esteem of high school students' magazine fundamentals of Mental Health, Vol. XIV, No. 2.

[33] Yeun, E., \&Jeon, M. (2015). Level of Depression and Anxiety among Undergraduate Students. Indian Journal of Science and Technology, Vol 8 (35), DOI: 10.17485/ijst/2015/v8i35/87313. 